\title{
An ethical approach to socio-economic information sources in ongoing vulnerability and resilience studies: the Mount Cameroon case
}

\author{
Maria Ilaria Pannaccione Apa ${ }^{1, \star}$, Emmanuel Kouokam² ${ }^{2}$, Robert Mbe Akoko ${ }^{3}$, \\ Celestin $\mathrm{Nana}^{4}$, Maria Fabrizia Buongiorno ${ }^{1}$ \\ ${ }^{1}$ Istituto Nazionale di Geofisica e Vulcanologia, Rome, Italy \\ ${ }^{2}$ Ministère de l'Industrie, des Mines et du Développement Technologique (MINIMIDT), Cameroon \\ ${ }^{3}$ University of Buea, Cameroon \\ ${ }^{4}$ Foundation of Applied Statistics and Data Management (FASTDAM), Cameroon
}

\section{Article history}

Received February 2, 2012; accepted March 27, 2012.

Subject classification:

Vulnerability, Resilience, Social recovery, Mount Cameroon, MIA-VITA Project.

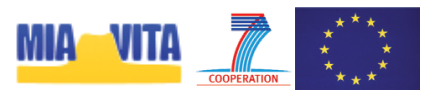

\section{ABSTRACT}

The study of the vulnerability of facing natural and man-made hazards, with the related resilient answers belong to the complex and articulate field of social sciences called 'Disaster Anthropology'. Vulnerability is generally defined as a weak point in facing an aggressive event that is difficult to manage. Resilience is the subsequent capacity for self-repair after a sustained natural or anthropogenic stress. Consequently, the theoretical model of economic resilience is the ability to restore an economic background that can support the gradual recovery of social benefits following a disaster. Moreover, the presence in the territory of different systems of production (natural eco-systems and/or technical systems) should allow multi-resilient communities. The mathematical structure of these economic theorems makes their practical application difficult inside an ethno-anthropological context, as it conflicts with cultural variables of the socio-structural fabric. An example can be given by some urban and rural family structures that are settled around the Mount Cameroon volcano (southwest Cameroon), in which the general psychological pressure increases because of both the constant exposure to natural hazards and the vulnerability arising from its social environment (e.g. castes, forced housing allocation, cultural estrangement to local chiefdom). Therefore, the rational heuristic model to be adopted in this social vulnerability study is performed by several combined analyses that have many interpretive obstacles. In 2009, within FP7-MIA-VITA, the first fieldwork mission for the study of socio-economic development of communities living around Mount Cameroon was launched. This completed 108 interviews across several social groups of different ethnicities and religions. The resulting information is being re-tested and verified from the second fieldwork mission in 2011, for completion of the study area.
1. Introduction to the social vulnerability and resilience concepts

Social vulnerability is generally defined as exposure to a hazard that is difficult to cope with. The main factors to be taken into account for human societies living in risk zones are (Figure 1):

(1) identification of vulnerable human and environmental conditions in facing a hazard [Burton et al. 1993, Anderson 2000];

(2) measurement of social resilience to hazards [Blaikie et al. 1994, Hewitt 1997];

(3) integration of potential exposure within related societal resilience on specific natural and/or anthropogenic environments [Kasperson et al. 1995, Cutter et al. 2000];

(4) ethno-anthropological characteristics (social vulnerability) [Cutter et al. 2001];

(5) soil and land use characteristics (biophysical vulnerability) [Cutter et al. 2001].

Resilience is the capability for self-repair after a sustained natural or anthropogenic stress. Consequently, the theoretical model of economic resilience is the ability to restore a productive background that can support the gradual recovery of social benefits following a disaster. In general, social groups also have different coping capacities, which enable them to reduce the potential of a hazard [Turner et al. 2003]. Generally, economic systems with different production capacities (as natural eco-systems and/or man-made systems) should theoretically allow multi-resilient community responses. Nevertheless, for 


\section{VULNERABILITY HAZARDS-OF-PLACE MODEL}

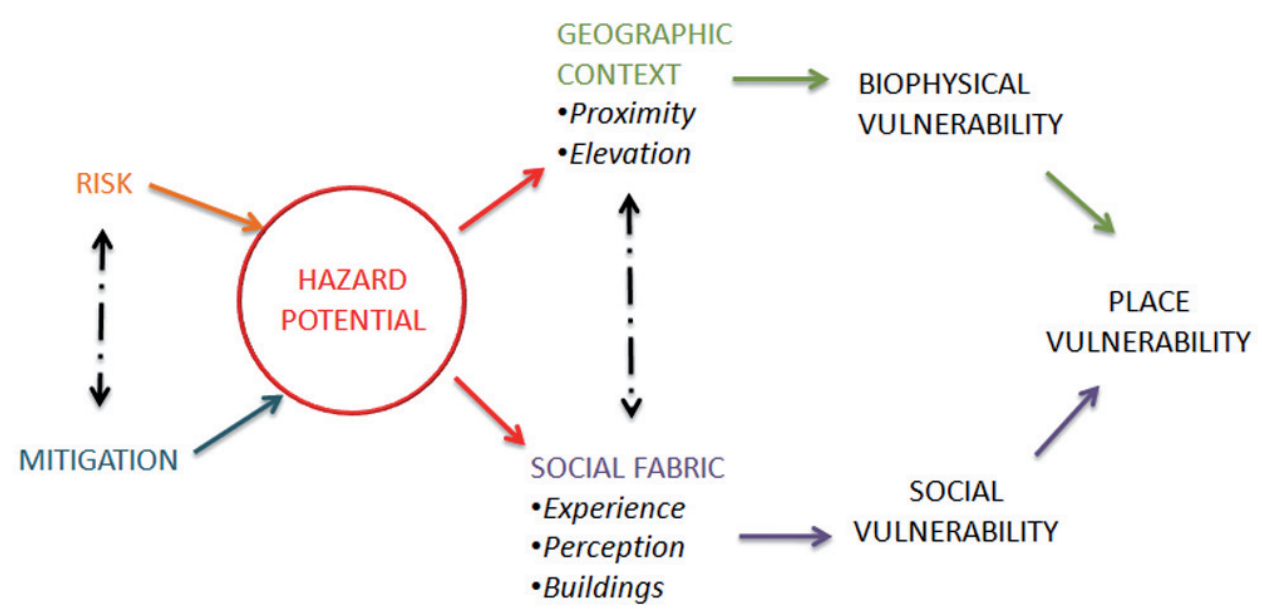

Figure 1. The 'Vulnerability Hazards-of-Place Model' of Cutter [1996] shows the structure and social dynamics in facing a hazard potential.

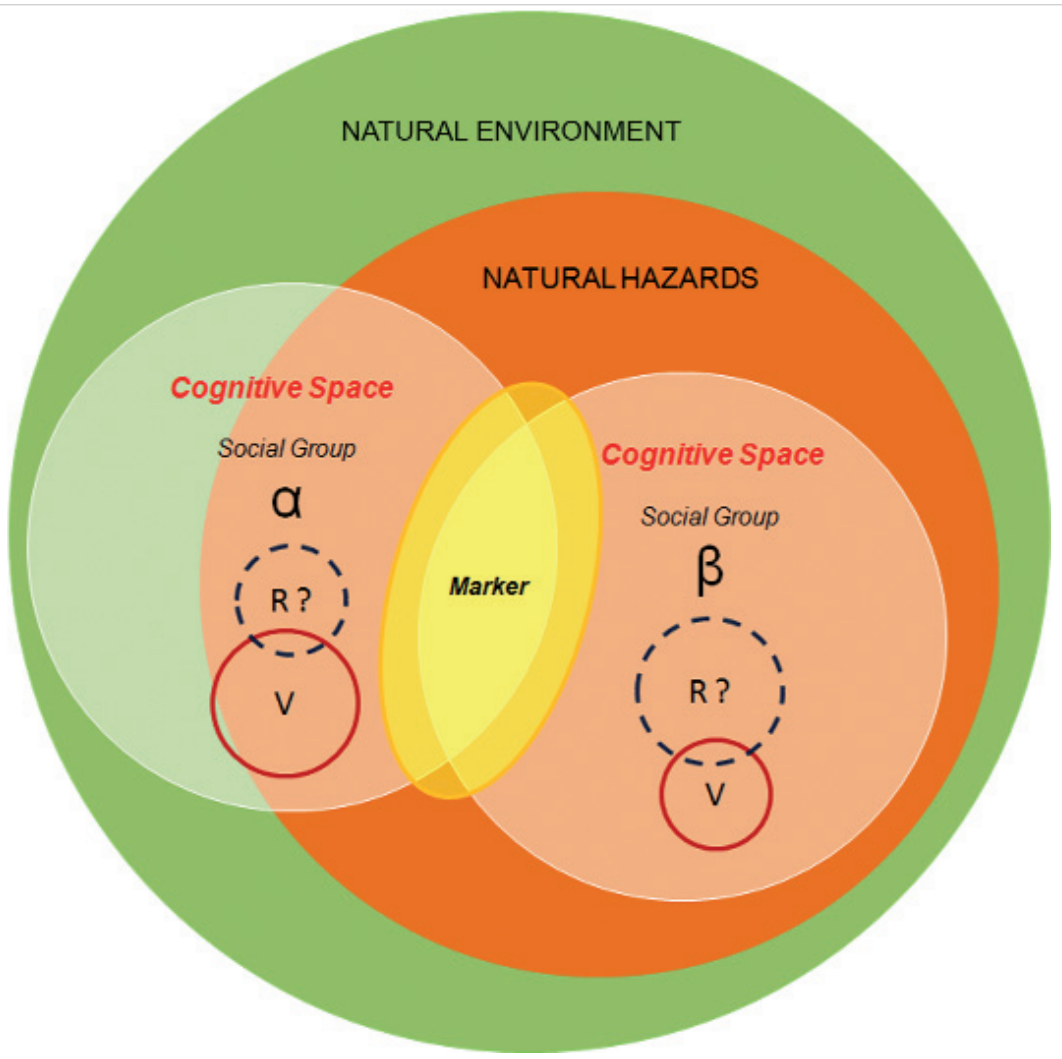

Figure 2. The Coping Capacities Theoretical Model, elaborated by Pannaccione Apa in 2011, suggests that resilient responses could not always directly proportional to level of exposure to risk and distance from a hazard source.

those that are ethno-traditionally based, the practical application of mathematics-based economic theorems [Kula 1980] might conflict with local cultural backgrounds and/or the ability for the application of practical self-repair models, because of the social fabric and causes arising from the location, such as the commercial and industrial development levels (Figure 2).

\section{The Mount Cameroon socio-economic vulnerability} and resilience approach study

The study carried out in the Mount Cameroon region (Figure 3) in southwest Cameroon, in the framework of the FP7 MIA-VITA Project ('Assess and mitigate risk from volcanic impact on terrain and human activities'; 2009-2010, 2011), was aimed at investigating socio-eco- 

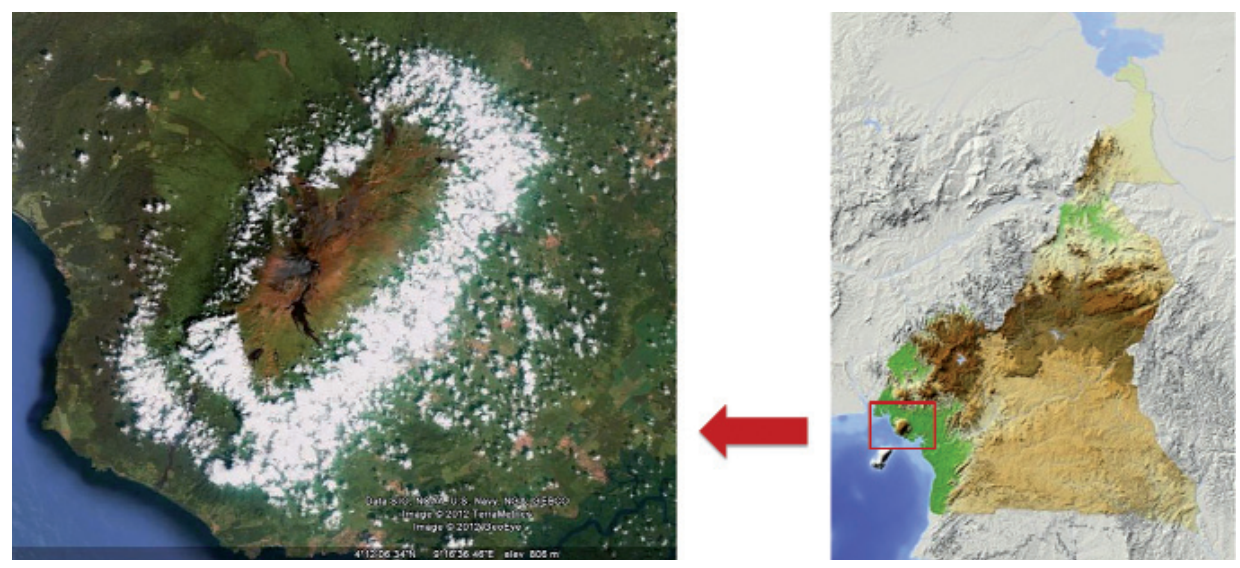

Above: Figure 3. Mount Cameroon (4095 $\mathrm{m}$ a.s.l.) is an active stratovolcano of dominantly basaltic composition (http:/ / www.volcano.si.edu/world/volcano.cfm?vnum=0204-01=). Photograph on the left: Google Earth. Shaded relief map of Cameroon on the right: NASA. Bottom: Figure 4. Natural hazards in the Fako region.

nomic vulnerability and resilience in risk zones mapped in the framework of the 'Gestion des Risques Naturels et Protection Civile' project carried out in 2006 by the Min- istry of Industry, Mines and Technological Development and the Bureau des Recherches Géologiques et Minières, France [Kouokam et al. 2011].

The test site is in the Fako division, which is exposed to a wide variety of natural hazards. In recent decades, the results of a retrospective study have shown a clear trend here for the proliferation and/or amplification of risks and disasters [Zogning et al. 2009] (Figure 4). The hazard exposure level and its distribution according to hazard types and geographical location are defined only according to the targeted hazards of the study that were effectively investigated using a representative sample; the rest, however, is strategically analyzed.

\section{ASH FALL}

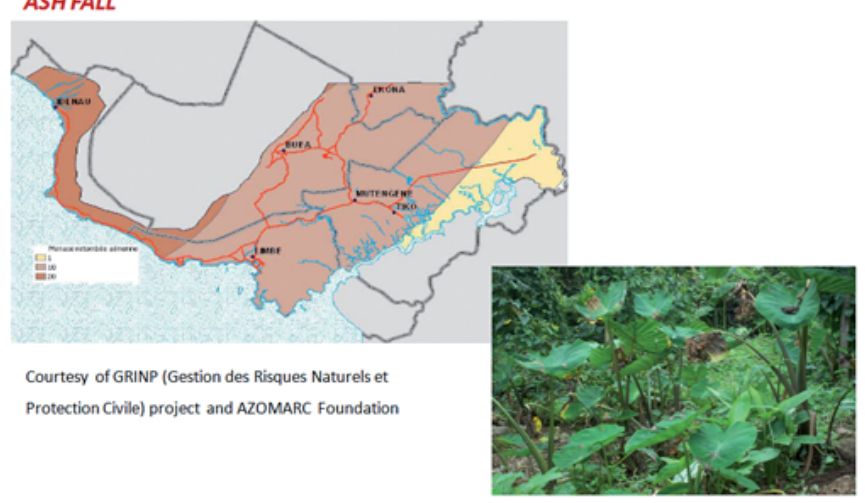

Colocasia sp. commonly known as IBO COCO' affected by ash coverage at Bonakanda. (Buea)

\section{NATURAL HAZARDS}

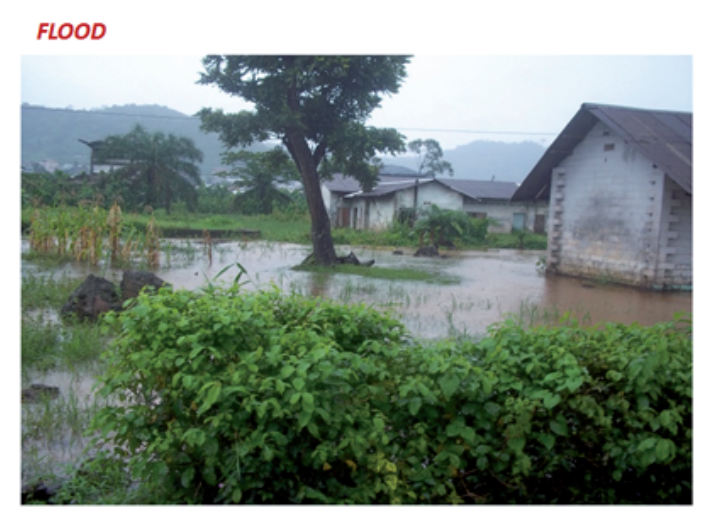

LAHAR
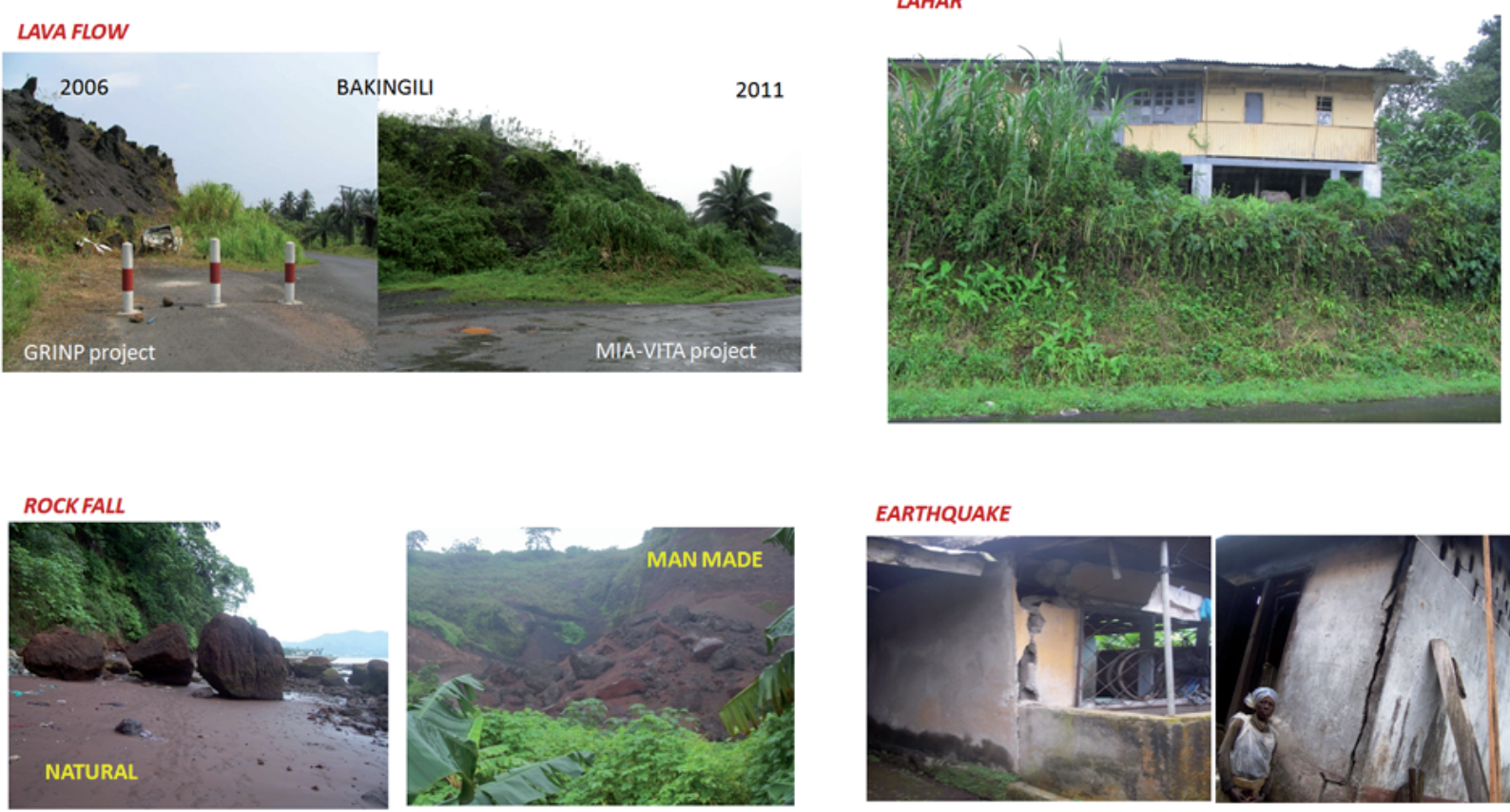

EARTHQUAKE

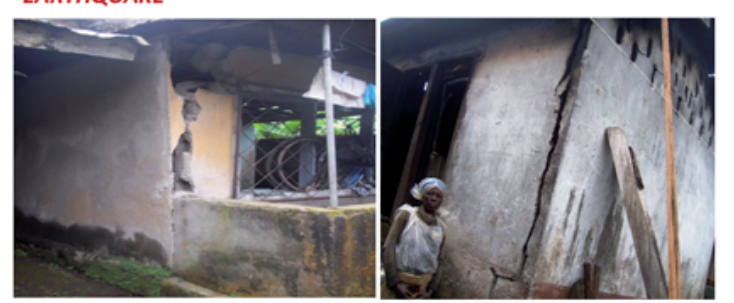


The expected outcome has been extrapolated using an appropriate approach that was expressed by combining both qualitative (heuristic method) and quantitative research methods for the construction of a mathematically binding model, the need to probe for indicators and respondent perceptions or viewpoints in detail in order to originate new theories or concepts besides those pre-established, and the vision of selecting among possible alternatives the most plausible scenario or range of scores that apply best to a given indicator. This approach should provide the best information to local people concerning the Mount Cameroon natural risks, and the necessary organized planning and prevention tools to help the local population and the local authorities to cope better with the risks. This includes reducing the community vulnerability in facing the natural hazards, and the performing of some appropriate social and economic resilience strategies according to local behavior, tradition and belief. Thirty-eight indicators were carefully selected as diagnostic, to evaluate the perception of vulnerability, the social fabric resilience, and the social stress factors [Kouokam et al. 2011]. All of the information was obtained by direct interviews conducted in Pidgin and English, which were then stored as specific questionnaires (Figure 5).

Finally, the data gathered (geological, hydrological, so-

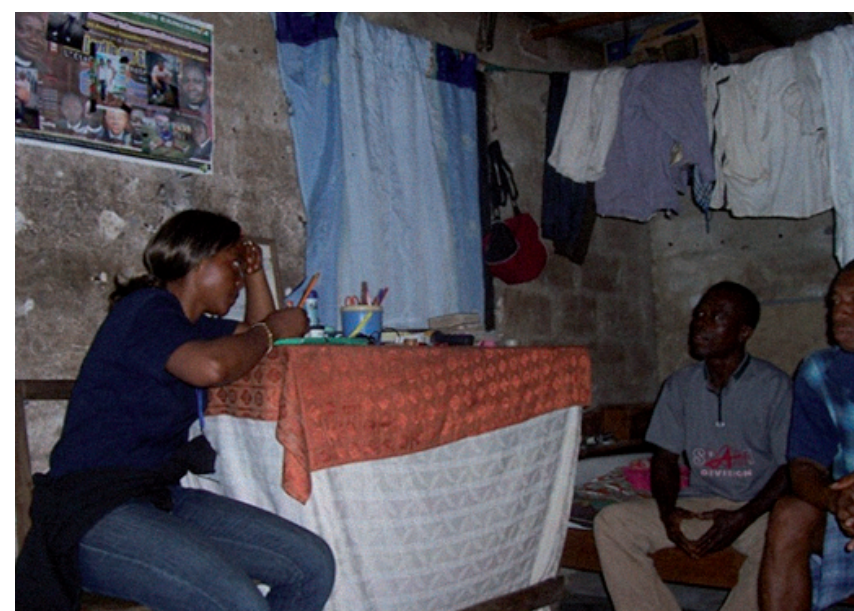

Figure 5. Project assistant Miss Sylvia Ngubienka'a (Buea University) conducting an interview in Pidgin in the Mapanja community (Buea) in the framework of the FP7 MIA-VITA 2nd fieldwork campaign, Fako division (Cameroon).

cial and ethnographic) were integrated into an interactive geographical information system (GIS) environment produced by Dr. Kouokam of the Ministère de l'Industrie, des Mines et du Développement Technologique and his staff, the MIA-VITA partner in Cameroon (Figure 6). All of the original texts are available as voice recordings and transcriptions, as well as the optional translation into English.

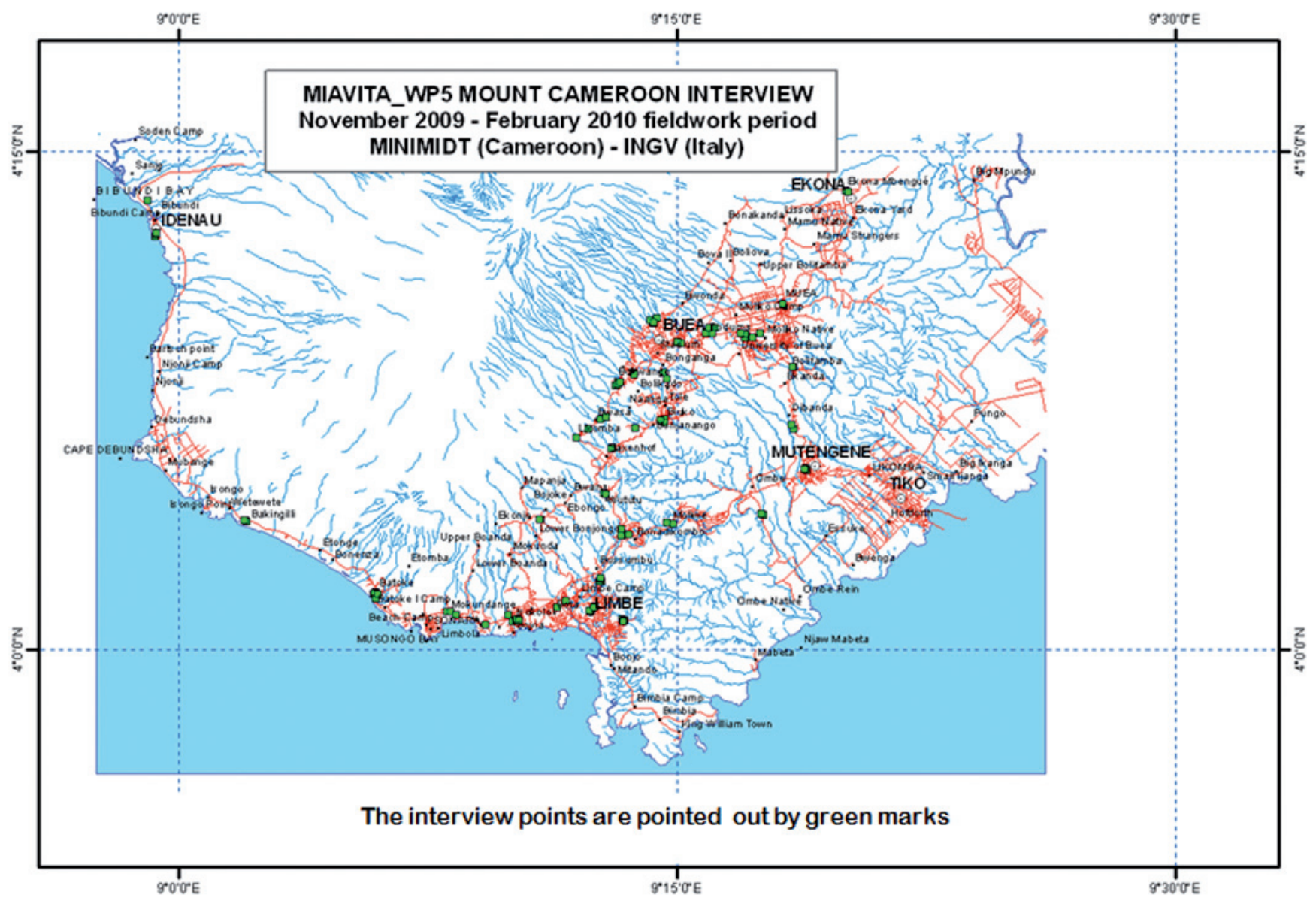

Figure 6. Interactive GIS environment of the Ministry of Industry, Mines and Technological Development produced after the first fieldwork campaign (2009-2010) in the framework of the FP7 MIA-VITA Project. 


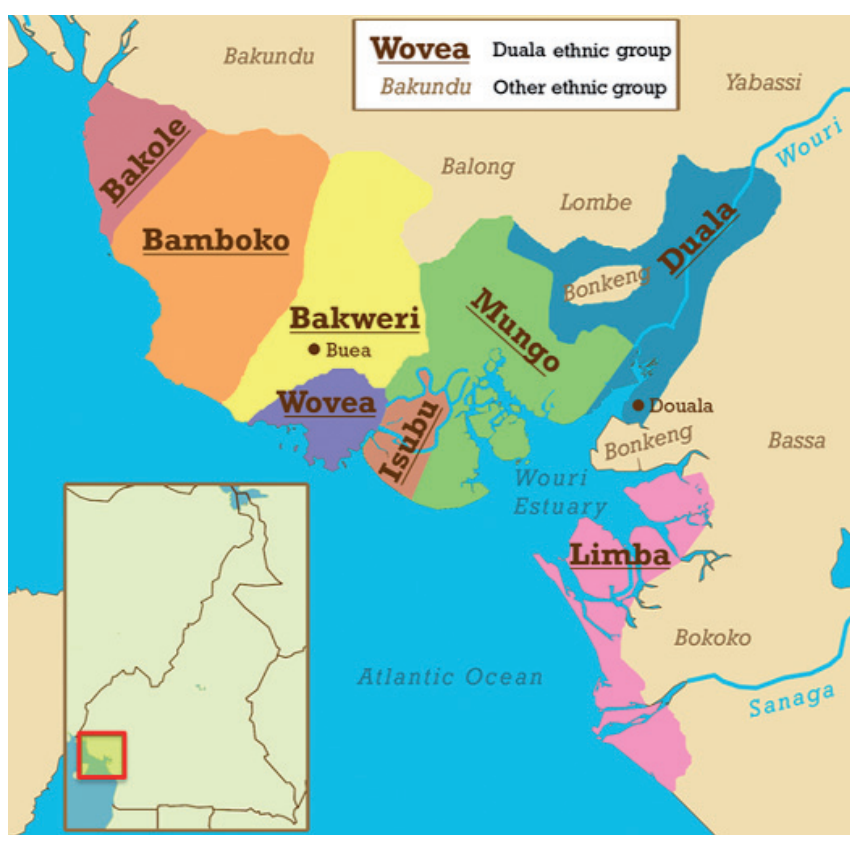

Figure 7. Ethno-linguistic group distribution of the southwest region of Cameroon (from http://en.wikipedia.org/wiki/Duala_people).

\section{Critical analysis to the ethical approach for dialogue with the social fabric of the Fako division}

During the investigation that led to the collection of the social vulnerability data, we had to overcome many obstacles through a qualified ethnological approach, to get honest answers from the local community. The topics (researchers to natives) were as follows:

1. Communication: in the local dialect;

2. Ethnicity: Fako division society is organized into several ethnic groups, with the two major ones being the Bakweri and Woveas, and with other minor ethnicities (Figure 7);

3. Social fabric: far from the urban settlements, villages are is generally managed by powerful chiefdoms who have a strong influence on the actions of their own ethnic group (Figure 8);

4. Kinship patterns: patrilineal. To have some information from women, special focus groups had to be organized where men did not participate.

5. Religion: Despite Bakweri being a Christian community since 1970 , animism is still practiced. Important beliefs must be respected to interact with local communities: Mount Cameroon is protected from a new eruption by a man-eater God named (Efasa) Epasa-Moto. It is believed that he controls the entire mountain from the west coast to the northeast coast. Epasa-Moto is described as a supernatural being who is half human and half mountain. He is the male half of the Goddess Liengu Mwanja, who is also called Nyago Namuna, who looks after the sea. Natural disasters are generally justified as the gods' reactions to evil deeds of men and to the violation of taboos (Figure 9).

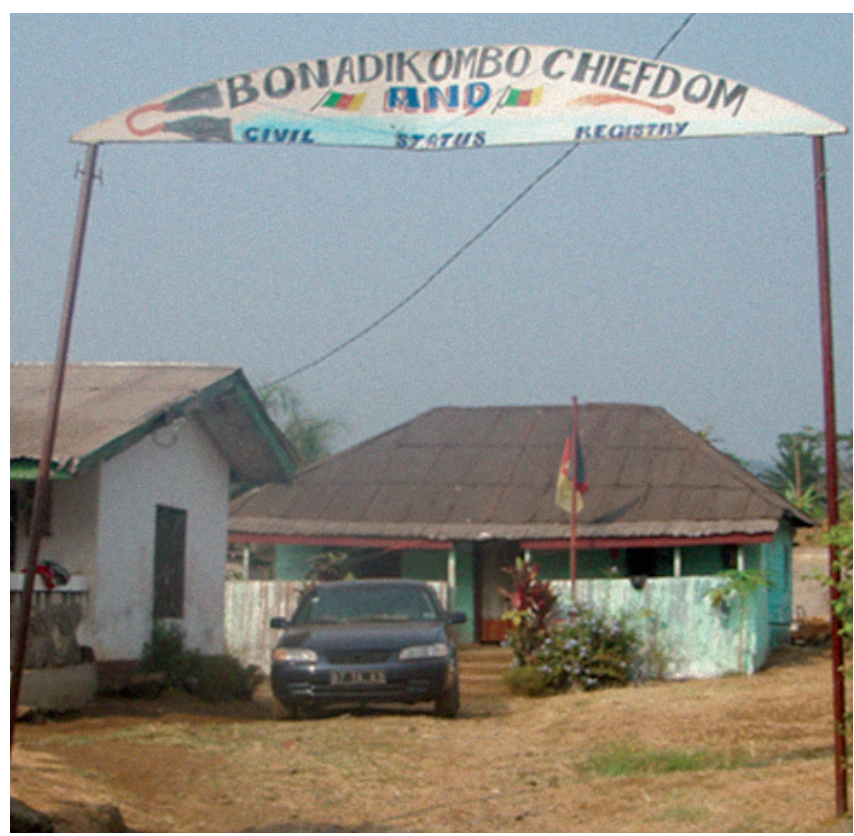

Figure 8. Visit to the Chiefdom of Bonadikombo during the first fieldwork mission.

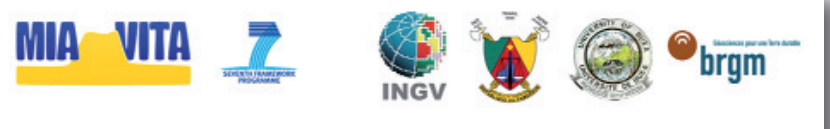

Chief of Batoke, interview of 28/01/2010:

How do you think the force can be of help to this hazard?

At the mountain we have EPASA MOTO, in the sea NIANGONAMUNA, we believe they protect us in times of hazard.

Is there a way to get in contact with this god or force? Who can do it? When? Why him/her/them?

To get in contact with the god, sacrifices are being made to the god, it's a tradition that has been left to us and we sacrifice fowls and goats and other things that i can't name them.

Figure 9. The answers of the Chief of Batoke suggest that despite the efforts of the Cameroon Civil Protection to raise the awareness to face natural hazards, the local risk perception comes from a strong historical memory that is still alive in tales and legends. Resilience strategies are delegated to divine intervention [Pannaccione Apa et al. 2011]. Despite the government ban on these practices, still now human beings are devoted to be sacrificed in some places, as young albino boys, while albino virgins are excluded.

\section{The vulnerabilities and capabilities of the people of} Mount Cameroon in facing volcanic hazards

To quote Kouokam et al. [2011] (unpublished; under FP7-MIAVITA copyright):

"In summary, no decrease in vulnerability was observed around the Mount Cameroon region several years after the eruption. An increase in vulnerability was instead 
observed, although this was not statistically significant. The population complained of a reduction in food production, increased poverty and unemployment, and of people settling continuously in disaster-prone areas. Moreover, no significant change in architectural design was seen, and resettlement or social actions to provide the population with safer social housing was not really effective.

A significant decrease in vulnerability and increase in resilience was observed with gas and acid rain. This group of hazards was indicated as the main cause of crop destruction years after the eruption. The community members adapted to this problem by shifting from Colocasia sp. and other tuber crops, such as cocoyam, to banana/plantain, although this was generally assessed as not sufficient to curb the problem of low food production.

The high fertility of the soil around Mount Cameroon favors the development of large-scale and small-scale farming, the availability of the sea enhances fishing activities, and natural resources like petrol, mineral water, and quarry sites are all potential natural factors that can help the population to recover from a hazard. This natural resilience is more pronounced because other predictors of resilience, such as economic status, local policies, or assistance in relation to disaster recovery, are highly lacking”.

\section{INTERVIEWS}

\section{OFFICIAL Authorities and traditional CHIEFDOMS}
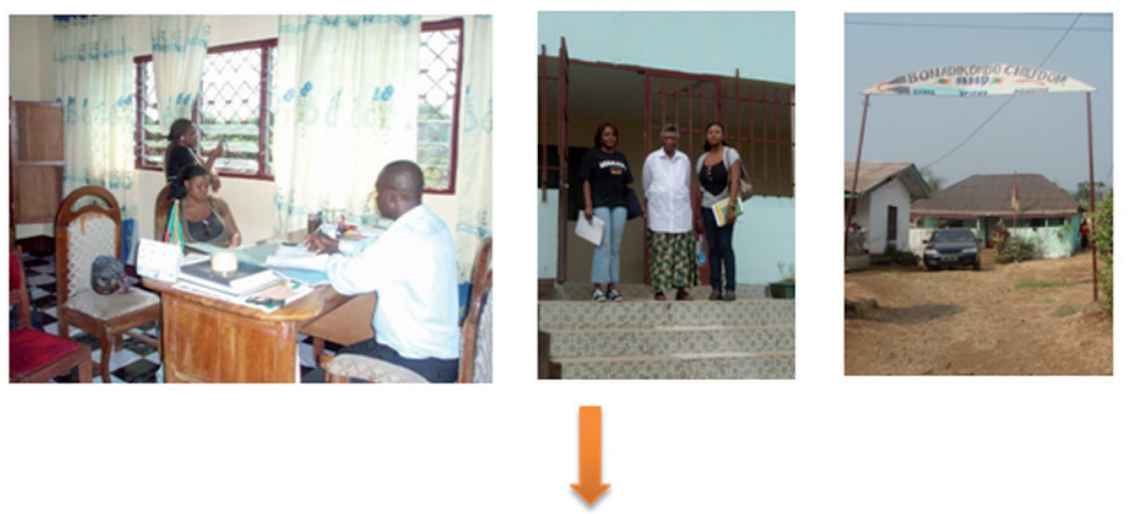

quarters, individuals, working communities
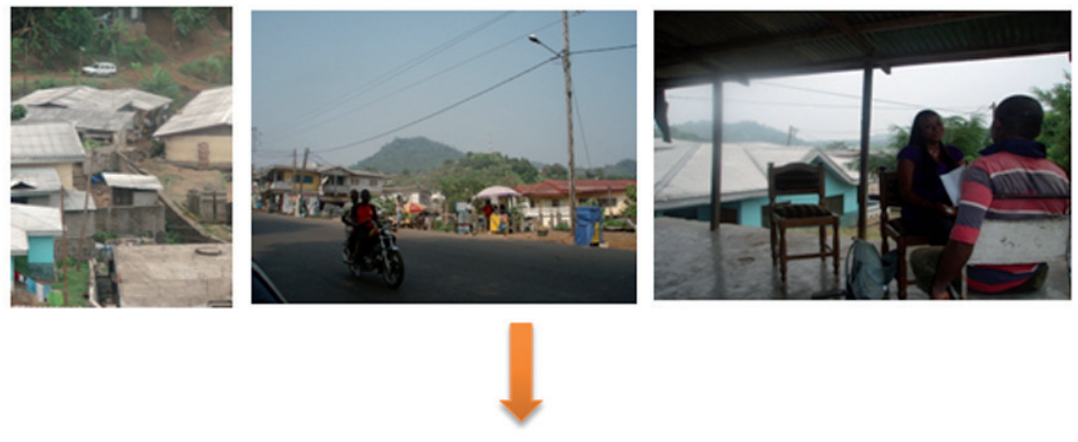

\section{Most of the selected respondents accepted the recording. For the minority which did not accept recording, responses have been transcribed.}
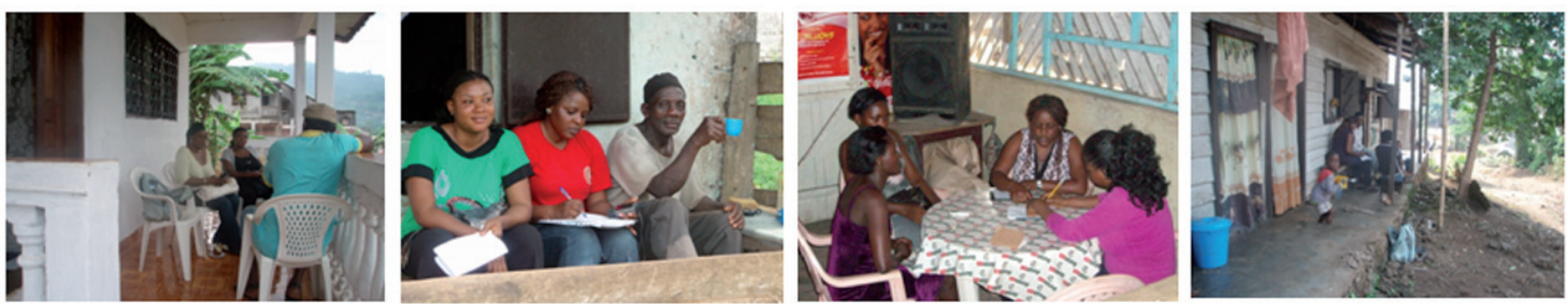

Figure 10. Philological approach to interviews and questionnaires in the framework of the FP7 MIA-VITA Project during the fieldwork campaigns in the Fako division [Pannaccione Apa et al. 2011]. 


\section{Conclusions}

The leitmotiv of this brief review was the ethno-anthropological classification based on the framework of social vulnerability and resilience analyses of the communities living around Mount Cameroon in the Fako division of Cameroon (Figure 10).

In summary, the human context is related to the volcano by a very close relationship of dependency. This includes the prevention of some incorrect social behaviors that generate the wrath of the volcano, and being grateful for the protection and conservation of an area that provides wealth in socio-economic terms. This strong relationship is attested by the periodic sacrifices that are offered to Epasa Moto (the God of Mount Cameroon) and Niangonamuna (the Goddess of the Sea), which are devoted to exorcise the fear of eruptions and tsunamis, turning negative into positive to give cultural sense and social priority to daily survival.

To summarize the experience, within the MIA-VITA Project, we had the opportunity to follow a philological social approach in Fako division that has produced some good results, such as:

(a) Risk mapping: available by GRINP (Gestion des Risques Naturels et Protection Civile) project;

(b) Social vulnerability-social indicators: according to the socio-economic components of the Fako division (the selected area);

(c) Social vulnerability-resilience data collection: 1163 key-informant questionnaires;

(d) Data processing: standard EPI-INFO, SPSS for the Social Vulnerability Index architecture;

(e) Social vulnerability-resilience result: interactive GIS environment.

The complete analyses and further studies are in progress and will be published at the end of the MIA-VITA Project.

Aknowledgements. Special thanks go to Prof. Matip (MINIMIDT) and Prof. Bobda for their assistance, valuable comments and constructive criticisms to the success of this work. Thanks to Governor's office of the South West Region, Statistics office, Buea Rural Council, Institute of Mining and Geological Research-Ekona and the Paramount Chief of the South West Region. Gratitude goes to social anthropologists of Buea University coordinated by Prof. Akoko which carried out the fieldwork data collection and communication with local people.

\section{References}

Anderson, M.B. (2000). Vulnerability to Disaster and Sustainable Development: A General Framework for Assessing Vulnerability, In: R. Pielke Jr. and R. Pielke Sr. (eds.), Storms, London: Routledge, vol. 1, 11-25.

Blaikie, P., T. Cannon, I. Davis and B. Wisner (1994). At Risk: Natural Hazards, People's Vulnerability, and Disasters, London, Routledge.

Burton, I., R.W. Kates and G.F. White (1993). The Envi- ronment as Hazard, 2nd ed., New York, Guildford.

Cutter, S.L. (1996). Vulnerability to Environmental Hazards, Progress in Human Geography 20 (4), 529-539.

Cutter, S.L., J.T. Mitchell and M.S. Scott (2000). Revealing the Vulnerability of People and Places: A Case Study of Georgetown County, South Carolina, Annals of the Association of American Geographers, 90 (4), 713-737.

Cutter, S.L., B. Boruff and W.L. Shirley (2001). Indicators of Social Vulnerability to Hazards; unpublished paper, Columbia, S.C.: University of South Carolina, Hazards Research Lab.

Hewitt, K. (1997). Regions of Risk: A Geographical Introduction to Disasters, Essex, U.K., Longman.

Kasperson, J.X., R.E. Kasperson and B.L. Turner (1995). eds. Regions at Risk: Comparisons of Threatened Environments, Tokyo, United Nations University Press.

Kouokam, E., C. Nana, M.I. Pannaccione Apa and R. Akoko (2011). Mt. Cameroon WP5 synthetic report, FP7 MIA-VITA project; unpublished, under EC copyright.

Kula, W. (1980). Teoria economica del sistema feudale, Torino, Einaudi.

Pannaccione Apa, M.I., E. Kouokam, R. Mbe Akoko, P. Thierry, M.F. Buongiorno (2011). Mt. Cameroon socioeconomic vulnerability and resilience assessment through traditional survey methods. [fp7-env-2007-1]; Project MIA-VITA (Mitigate and assess risk from volcanic impact on terrain and human activities), Vienna, EGU 2011, poster session, published.

Turner, B.L., R.E. Kaspersonb, P.A. Matson, J.J. McCarthy, R.W. Corell, L. Christensene, N. Eckley, J.X. Kasperson, A. Luers, M.L. Martello, C. Polsky, A. Pulsipher and A. Schillerb (2003). A Framework for Vulnerability Analysis in Sustainability Science, In: Proceedings of the National Academy of Sciences of the United States of America (PNAS), 100 (14), 8074-8079.

Zogning, A., C. Spinetti, Ch. Ngouanet, D. Tchoudam, P. Thierry, Ch. Bignami, E. Kouokam, M.F. Buongiorno and M.I. Pannaccione Apa (2009). Risks Prevention Plans (RPP) and the vulnerability of peoples around volcanoes: Case study of Mt. Cameroon; Author manuscript, published in: First international conference "Volcanoes Landscapes and cultures", Catania, Italy (2009).

*Corresponding author: Maria Ilaria Pannaccione Apa, Istituto Nazionale di Geofisica e Vulcanologia, Rome, Italy; email: mariailaria.pannaccioneapa@ingv.it.

(C) 2012 by the Istituto Nazionale di Geofisica e Vulcanologia. All rights reserved. 